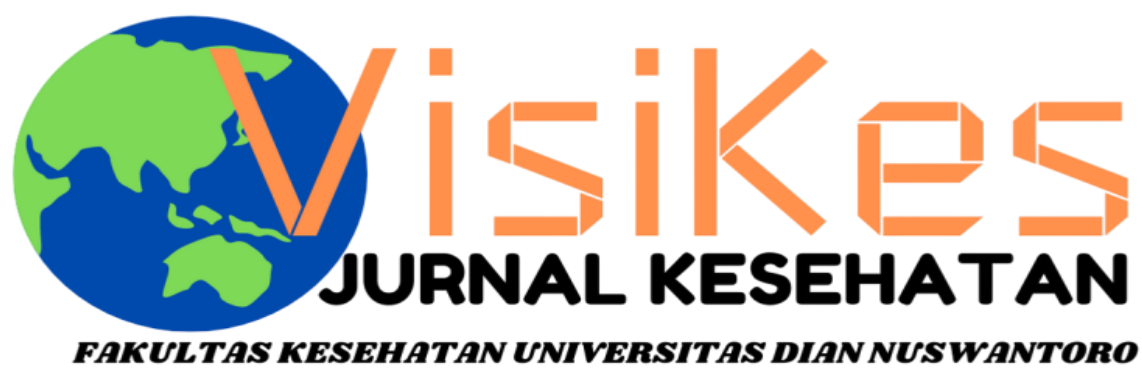

ISSN 1412-3746

FAKULTAS KESEHATAN UNIVERSITAS DIAN NUSWANTORO

Persepsi Mahasiswa Keperawatan Tentang Eskalasi Tenaga Perawat

Rendi Ariyanto Sinanto', Vivi Retno Intening ${ }^{2}$

Risiko kesehatan $\mathrm{Pb}$ dan $\mathrm{Hg}$ pada sayuran di desa Kopeng Kabupaten Semarang

Indira Casheila Anindityo ${ }^{1}$, Nur Endah Wahyuningsih ${ }^{2}$, Yusniar Hanani Darundiati ${ }^{3}$

Analisis Pelaksanaan Program Indonesia Sehat Dengan Pendekatan Keluarga (Pispk) Dalam Capaian Indeks Keluarga

Sehat Di Kabupaten Brebes Tahun 2020 Studi Pada Puskesmas Kluwut Kabupaten Brebes

Rizky Aprilianti Lestari ${ }^{1}$ dr. Antono Suryoputro ${ }^{1}$ Dr. dr. Apoina Kartini. M. Kes ${ }^{1}$

Disiplin Keselamatan dan Kesehatan Kerja melalui pemakaian alat pelindung diri di laboratorium kimia PT Sucofindo

Jakarta

Susan Endah Kartikasari ${ }^{1}$, Tatan Sukwika ${ }^{2}$

Perbedaan Pengetahuan Anemia dan Tablet Tambah Darah (TTD) Sebelum dan Sesudah Pendidikan Kesehatan Melalui

Media Video dan Aplikasi Quizlet

Devita Sari ${ }^{1}$, Gisely Vionalita ${ }^{2}$

Tingkat Pengetahuan Dan Perilaku Mahasiswi Mengenai Legalitas Dan Keamanan Kosmetik

Hani Sri Fitriani, Rizki Siti Nurfitria

Evaluasi Manajemen Dokumen Rekam Medis Di Filing Aktif Rumah Sakit Swasta Kabupaten Semarang

Bobby Anggara Laksana Putra ${ }^{1}$, Retno Astuti Setjaningsih ${ }^{2}$

Tingkat Pengetahuan Gizi Seimbang dan Profil Kesehatan Sopir Bus Antar Kota

Vilda Ana Veria Setyawati ${ }^{1}$, Bayu Yoni Setyo Nugroho ${ }^{1}$

Pengaruh Pengetahuan Dan Motivasi Kerja Terhadap Penerapan Early Warning Score System Di Rsup H Adam Malik Ita Riahna Pinem ${ }^{1}$, Zulfendri', Siti Saidah Nasution ${ }^{3}$

Analisis Penelusuran Masker Sebagai Protokol Kesehatan Saat Pandemi Covid-19 Di Indonesia: Studi Google Trends Ully Febra Kusuma ${ }^{1}$, Nurunnisa Arsyad ${ }^{2}$, Melissa Shalimar Lavinia ${ }^{3}$, Selvia Rahayu ${ }^{4}$, M. Khairul Kahfi , Rizma Adllia Syakurah ${ }^{6}$ Perilaku Hidup Bersih Dan Sehat (Phbs) Dengan Kejadian Sakit Pada Siswa Sekolah Dasar Di Kabupaten Banyumas Windri Lesmana Rubai ${ }^{1}$, Pramesthi Widya Hapsari', Katri Andirini Surijati ${ }^{3}$

Identifikasi Risiko Ganguan Muskuloskletal Pada Pekerja Percetakan Dengan Metode Nordic Body Map

Octavianus Hutapea ${ }^{1}$, Moch.Sahri', Rustam Basuki ${ }^{3}$

Literatur review: Implementasi Bauran Pemasaran 7P Terhadap Tingkat Kepuasan Pasien Di Rumah Sakit

Desi Natalia Marpaung ${ }^{1}$ Ernawaty $^{2}$ Diansanto Prayoga ${ }^{3}$ Syifa'ul Lailiyah $^{4}$

Kelengkapan Informasi Medis Untuk Mendukung Kodefikasi Penyakit Jantung Guna Mewujudkan Kualitas Data Informasi Medis Di Rumah Sakit Islam Sultan Agung Semarang

Dyah Ernawati ${ }^{1}$, Ratna Rifatul Ulya ${ }^{2}$, Arif Kurniadi ${ }^{3}$

Kajian Faktor Kendala Dokter Tidak Menggunakan Aplikasi Wifi Tb Di Kota Semarang

Arif Kurniadi', Evina Widianawati2, Dyah Ernawati ${ }^{3}$

Analisis Pelaksanaan Program Penanggulangan Tuberkulosis Paru Di Puskesmas Purwoyoso Kota Semarang

Nahari Ratu Cempaka Wilis ${ }^{1}$ Hardi Warsono ${ }^{2}$ M. Sakundarno Adi ${ }^{3}$

Hubungan Penggunaan Alat Pelindung Diri (Apd) Dengan Kadar Sgot Dan Sgpt Dalam Darah Pada Petani Padi

Iga Maliga, Rafi'ah

Faktor Risiko Kejadian Stunting Pada Balita di Wilayah Kerja Puskesmas Pandan Kabupaten Sintang

${ }^{1}$ Agustini Elisabet, ${ }^{2}$ Elvi Juliansyah

Peran Suami Dan Petugas Kesehatan Dengan Deteksi Dini Kanker Serviks

Christina Leasa, ${ }^{1}$ Mariene Wiwin Dolang

Analisis Penerapan Protokol Kesehatan terhadap Tingkat Kepatuhan Pada Pekerja informal Selama Pandemi Covid-19

MG Catur Yuantari ${ }^{1}$, Enny Rachmani ${ }^{2}$, Eti Rimawati ${ }^{1}$, Sri Handayani ${ }^{1}$, Edi Jaya Kusuma ${ }^{2}$

Peran Pengawas Minum Obat Dan Pendampingan Berobat Ulang Dengan Keberhasilan Pengobatan Tb Paru

Taswin $^{\left.1^{*}\right)}$, (zan $^{1)}$, Wahyuddin $^{1)}$, Dahmar ${ }^{1)}$

Faktor Determinan Sosial Dan Gambaran Kejadian Post Traumatic Syndrome Disorder (Ptsd) Pasca Banjir Di Dki Jakarta

Dan Bekasi Tahun 2020

Thresya Febrianti ${ }^{1}$, Nurfadhillah ${ }^{2}$, Mitha Nurhjanah ${ }^{3}$, Tiara Kautsa Aliefya ${ }^{4}$

Perbedaan Pola Makan Pada Balita Stunting Dan Tidak Stunting Di Kecamatan Teon Nila Serua (Tns) Kabupaten Maluku Tengah

Trixie Leunupun ${ }^{1}$, Ani Margawati' ${ }^{2}$ Annastasia Ediati ${ }^{3}$

Gambaran Pengelolaan Rekam Medis Rawat Inap Di Rsud Syekh Yusuf Kab. Gowa Tahun 2019

Zilfadhilah Arranury*, Surahmawati, Muhammad Rusmin, Tri Addya Karini, Dian Rezki Wijaya, Ranti Ekasari, Jihan Sulfitri

Analisis Risiko Kesehatan dalam Pemanfaatan Kemball Limbah Sludge Industri Makanan PT. X

Sri Slamet Mulyati ${ }^{1}$, Fajar Sihite ${ }^{2}$ 


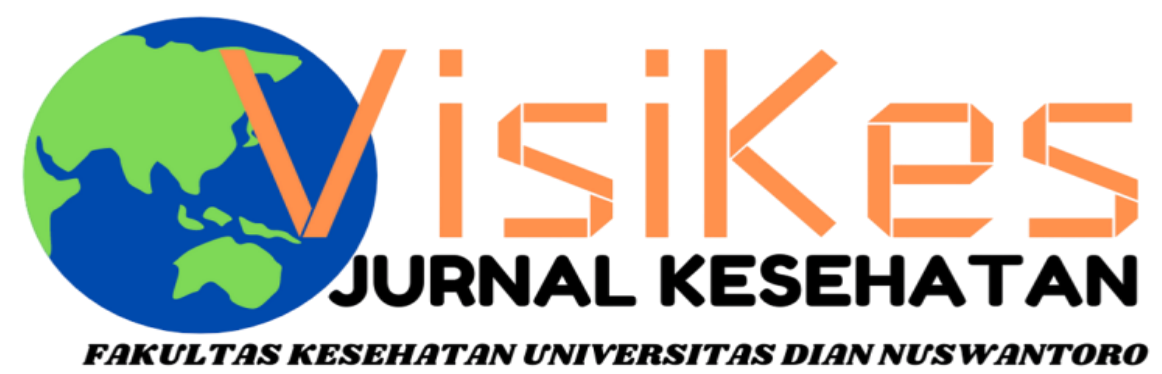

Volume 20, Nomor 1, April 2021

\section{Ketua Redaksi}

Dr. Drs. Slamet Isworo, M.Kes

\section{Penyunting}

Enny Rachmani, SKM, M.Kom, Ph.D

Fitria Wulandari, SKM, M.Kes

\section{Sekretariat}

Lice Sabata, SKM

Desain dan Layout

Puput Nur Fajri, SKM

\section{Alamat Redaksi}

Fakultas Kesehatan Universitas Dian Nuswantoro Jl. Nakula I No. 5-11 Semarang Telp/fax. (024) 3549948

email : visikes@fkes.dinus.ac.id

website $\quad$ : http://publikasi.dinus.ac.id/index.php/visikes/index

VisiKes diterbitkan mulai Maret 2002

Oleh Fakultas Kesehatan Universitas Dian Nuswantoro 


\title{
Perbedaan Pengetahuan Anemia dan Tablet Tambah Darah (TTD) Sebelum dan Sesudah Pendidikan Kesehatan Melalui Media Video dan Aplikasi Quizlet
}

Devita Sari ${ }^{1}$, Gisely Vionalita ${ }^{2}$

1,2 Program Studi Kesehatan Masyarakat, Fakultas IImu-ilmu Kesehatan

Universitas Esa Unggul

Email: gisely@esaunggul.ac.id

\begin{abstract}
The problem of anemia in adolescent girls will have a negative impact on decreased learning concentration and later pregnancy. Based on data of Indonesian Demographic and Health Survey (SDKI) in 2017, only $8 \%$ of young women answered correctly about the meaning of anemia and 23.4\% answered they did not know about the cause of anemia. This study aims to determine differences in student's knowledge about anemia and Blood Booster Tablets (TTD) before and after health education through video media and Quizlet Applications. This research uses Quasi Experimental Design with One Group Pretest Posttest. The sampling technique used Stratified Random Sampling with sampel 30 respondents. The results of the T-Dependent tests showed that there were differences in student's knowledge about anemia and Blood Booster Tablets (TTD) before and after health education through video media and Quizlet Application, with a p-value 0,000. It is expected that Health Center and Schools can work together in providing health education through video media and Quizlet Application by holding a Healthy Friday Program and the Health Center can employ specialized human resources educated in Information Technology (IT) to develop video media and online-based applications.
\end{abstract}

Keywords: Quizlet Application, Health Education, Anemia Knowledge, Adolescent, The Video

\begin{abstract}
ABSTRAK
Masalah anemia pada remaja putri akan berdampak negatif terhadap menurunnya konsentrasi belajar dan masa kehamilan kelak. Berdasarkan data Survei Demografi dan Kesehatan Indonesia (SDKI) tahun 2017, hanya $8 \%$ remaja putri yang menjawab benar mengenai arti anemia dan $23,4 \%$ menjawab tidak tahu mengenai penyebab anemia. Penelitian ini bertujuan untuk mengetahui perbedaan pengetahuan siswi tentang anemia dan Tablet Tambah Darah (TTD) sebelum dan sesudah pendidikan kesehatan melalui media video dan Aplikasi Quizlet. Penelitian ini menggunakan desain Quasi Eksperimental dengan rancangan One Group Pretest Posttest. Teknik pengambilan sampel dengan Stratified Random Sampling dengan jumlah sampel sebanyak 30 responden. Hasil penelitian dari uji T-Dependent menunjukkan terdapat perbedaan pengetahuan siswi tentang anemia dan Tablet Tambah Darah (TTD) sebelum dan sesudah pendidikan kesehatan melalui media video dan Aplikasi Quizlet yaitu dengan nilai p-value 0,000. Diharapkan Puskesmas dan Pihak Sekolah dapat bekerja sama dalam memberikan pendidikan kesehatan melalui media video dan Aplikasi Quizlet dengan mengadakan Program Jum'at Sehat dan Puskesmas dapat mempekerjakan SDM khusus berpendidikan IT untuk mengembangkan media video dan aplikasi berbasis online.
\end{abstract}

Kata Kunci: Aplikasi Quizlet, Pendidikan Kesehatan, Pengetahuan Anemia, Remaja, Video

\section{PENDAHULUAN}

Ketika konsentrasi hemoglobin atau sel darah merah di bawah normal maka hal tersebut dikatakan anemia menurut $\mathrm{WHO}$. $^{(1)}$ Data WHO tahun 2011, 500 juta wanita di dunia atau dengan perbandingan satu dari tiga wanita tidak hamil mengalami anemia.(2) Di setiap negara prevalensi remaja yang mengalami anemia bervariasi yaitu sekitar $17 \%$ sampai $90 \%$. Diketahui di negara-negara Asia Tenggara (kecuali Thailand) seperempat remaja mengalami anemia. ${ }^{(3)}$ Berdasarkan 
data Riskesdas 2013, pada wanita yang berusia 13 sampai 18 tahun memiliki resiko terkena anemia gizi besi sebesar $22,7 \%$. $^{(4)}$

Berdasarkan SDKI, pengetahuan tentang anemia dirincikan menjadi tiga bagian yaitu pemahaman anemia, penyebab anemia dan cara mengatasi anemia. Sebagian besar wanita memiliki pemahaman yang kurang tentang anemia. Berdasarkan data SDKI 2017, diketahui ada $73 \%$ wanita mempunyai pemahaman bahwa anemia adalah kurang darah. Diketahui juga hanya ada $8 \%$ wanita yang menjawab benar arti anemia, sedangkan pada SDKI 2012 diketahui ada 25\% wanita yang menjawab benar arti anemia. ${ }^{(5)}$ Dapat disimpulkan ada penurunan $17 \%$ pemahaman wanita tentang anemia dari tahun 2013 ke tahun 2017. Ketika wanita berusia 15-19 tahun ditanya mengenai pengetahuan tentang penyebab anemia $23,4 \%$ menjawab tidak tahu dan ketika ditanya mengenai pengetahuan cara mengatasi anemia $14 \%$ menjawab minum tablet besi. ${ }^{(6)}$

Hasil survei pendahuluan yang dilakukan pada 16 September 2019 melalui penyebaran kuesioner kepada 20 siswi di Madrasah Aliyah Al-Falah mengenai pengetahuan anemia dan Tablet Tambah Darah (TTD) diketahui bahwa 70\% siswi menjawab salah mengenai pengetahuan tentang gejala anemia, 65\% siswi menjawab salah mengenai pengetahuan tentang cara mengatasi anemia dan $65 \%$ siswi menjawab salah mengenai aturan minum TTD. Diketahui pula terdapat 19 siswi merasa tidak semangat belajar akibat mengalami gejala anemia yaitu lelah, letih dan lesu dan 17 siswi merasa sulit konsentrasi dalam belajar. Berdasarkan wawancara dengan Wakil Kepala Madrasah, diketahui saat upacara bendera yang berlangsung pada hari senin rata-rata ada 2-3 siswi mengalami pingsan dengan gejalagejala terkena anemia.

Meningkatkan pengetahuan anemia melalui pendidikan kesehatan merupakan salah satu upaya untuk mencegah terjadinya anemia pada remaja. Hasil tahu seseorang melalui indera yang dimiliki terhadap suatu objek disebut pengetahuan, intensitas perhatian dan persepsi terhadap objek dapat mempengaruhi pengetahuan tersebut. ${ }^{(7)}$ Menurut penelitian Caturiyantingtiyas, terdapat hubungan yang bermakna antara tingkat pengetahuan dengan kejadian anemia putri. $^{(8)}$ Diketahui dari penelitian Kusuma, pendidikan kesehatan tentang anemia memiliki pengaruh terhadap pengetahuan remaja putri dalam mencegah anemia. ${ }^{(9)}$

Seiring dengan kemajuan teknologi, mulai dikembangkan sarana pendidikan kesehatan salah satunya penggunaan video. Kelebihan dari media video yaitu dapat memberikan visualisasi yang baik sehingga memberikan kemudahan dalam proses penyerapan pengetahuan. ${ }^{(10)}$ Pada era milenial, remaja juga tidak dapat dilepaskan dari smartphone maka dari itu dibuatlah media pembelajaran berbasis mobile salah satunya Aplikasi Quizlet. Maka dari itu peneliti akan melakukan intervensi pendidikan kesehatan melalui media video dan Aplikasi Quizlet.

Didukung oleh beberapa penelitian, menurut penelitian Saban yang melakukan perbandingan media yang efektif dalam penyuluhan, dapat disimpulkan lebih efektif media video dibandingkan leaflet pada 
penyuluhan tentang anemia. ${ }^{(11)}$ Sejalan dengan penelitian tersebut, Cahyono menyatakan bahwa adanya pengaruh pendidikan gizi yang diberikan melaui media video pada pengetahuan siswi sebelum dan sesudah tentang anemia.(12) Menurut penelitian Wardana menyatakan bahwa siswa yang menggunakan media pembelajaran dengan Aplikasi Quizlet memiliki respon belajar yang lebih baik dibandingkan menggunakan media konvensional. ${ }^{(13)}$

Oleh karena itu berdasarkan perkembangan zaman era milenial 4.0 dan didukung oleh beberapa penelitian, maka pada penelitian ini penulis ingin menbahas "Perbedaan Pengetahuan Siswi Tentang Anemia Dan Tablet Tambah Darah (TTD) Sebelum dan Sesudah Pendidikan Kesehatan Melalui Media Video dan Aplikasi Quizlet Di Madrasah Aliyah Al-Falah Tahun 2019".

\section{METODE PENELITIAN}

Penelitian ini adalah penelitian kuantitatif dengan menggunakan desain penelitian Quasi Ekperimental dengan rancangan One Group Pretest Posttest. Penelitian dilakukan di Madrasah Aliyah AlFalah pada bulan September 2019 - Januari 2020. Populasi dalam penelitian ini berjumlah HASIL
98 orang yaitu seluruh siswi kelas $\mathrm{X}$ dan $\mathrm{XI}$ di Madrasah Aliyah Al-Falah.

Teknik pengambilan

sampel menggunakan Stratified Random Sampling berdasarkan dengan kriteria inklusi yaitu sampel berjenis kelamin perempuan, siswi kelas X dan XI Madrasah Aliyah Al-Falah dan tercatat di dalam absensi sedangkan kriteria eksklusi yaitu siswi tidak hadir saat penelitian berlangsung dan tidak bersedia menjadi responden. Sampel yang digunakan berjumlah 30 siswi.

Pada sampel pengetahuan tentang anemia ditest dua kali yaitu sebelum dan sesudah intervensi. Intervensi berupa pendidikan kesehatan melalui media video dan Aplikasi Quizlet. Video ditayangkan setelah siswa mengisi pretest berupa video animasi yang berdurasi kurang lebih 8 menit mengenai anemia dan TTD. Setelah penayangan video, peneliti mengulang materi yang terdapat di video dengan media pembelajaran Aplikasi Quizlet. Aplikasi ini merupakan metode permainan kuis yang digunakan peneliti untuk merangsang stimulus responden dalam meningkatkan pemahaman terhadap pengetahuan anemia dan TTD.

Analisis Univariat

Tabel 1. Distribusi Pengetahuan Siswi Tentang Anemia dan Tablet Tambah Darah (TTD) Sebelum dan Sesudah Pendidikan Kesehatan

\begin{tabular}{cccccc}
\hline Variabel & N & Mean & SD & Min & Max \\
\hline Pengetahuan Sebelum Pendidikan Kesehatan & 30 & 63,33 & 11,167 & 40 & 80 \\
\hline Pengetahuan Sesudah Pendidikan Kesehatan & 30 & 86,50 & 8,725 & 65 & 100 \\
\hline
\end{tabular}

Berdasarkan Tabel 1, diketahui dari 30 siswi diperoleh nilai rata-rata pengetahuan sebelum diberikan pendidikan kesehatan (pretest) adalah 63,33 dengan standar deviasi sebesar 11,167, nilai minimal sebesar 40 dan nilai maksimal sebesar 80 . Sedangkan nilai rata-rata pengetahuan sesudah diberikan pendidikan kesehatan (post-test) adalah 
86,50 dengan standar deviasi sebesar 8,750, nilai minimal sebesar 65 dan nilai maksimal sebesar 100.

\section{Analisis Bivariat}

Analisis bivariat ada berbagai macam untuk mengetahui hal tersebut maka harus dilakukan uji normalitas. Uji untuk mengetahui data yang digunakan terdistribusi normal atau tidak disebut uji normalitas. Dalam hasil penelitian ini menggunakan uji Normalitas Shapiro-Wilks. Data hasil uji normalitas dapat dilihat pada Tabel 2.

Tabel 2. Hasil Uji Normalitas

\begin{tabular}{cc}
\hline Variabel & $\boldsymbol{P}$-value \\
\hline Pengetahuan Sebelum Pendidikan Kesehatan & 0.027 \\
\hline Pengetahuan Sesudah Pendidikan Kesehatan & 0.074 \\
\hline
\end{tabular}

Berdasarkan Tabel 2, dalam menentukan uji yang digunakan untuk analisis perbedaan pengetahuan sebelum dan sesudah pendidikan kesehatan, peneliti menggunakan uji normalitas pada pengetahuan sesudah pendidikan kesehatan, hal itu berarti $p$-value $>0,05$ sehingga data terdistribusi normal. Jika data terdistribusi normal maka analisis bivariat menggunakan uji T-Dependent.

Tabel 3. Distribusi Perbedaan Pengetahuan Siswi Tentang Anemia dan Tablet Tambah Darah (TTD) Sebelum dan Sesudah Pendidikan Kesehatan Melalui Media Video dan Aplikasi Quizlet

\begin{tabular}{ccccc} 
Variabel & SD & $\begin{array}{c}\text { Beda } \\
\text { Rata-rata }\end{array}$ & 95\% Cl Beda Rata-rata & P-value \\
\hline $\begin{array}{l}\text { Pengetahuan Sebelum } \\
\text { Pengetahuan Sesudah }\end{array}$ & 11,102 & 23,167 & $-27,312--19,021$ & 0.000 \\
\hline
\end{tabular}

Berdasarkan Tabel 3 diketahui dari 30 siswi diperoleh nilai rata-rata perbedaan antara pengetahuan sebelum (pre-test) dan sesudah (post-test) diberikan pendidikan kesehatan adalah 23,167 dengan standar deviasi sebesar 11,102, hal itu berarti ada peningkatan pengetahuan sesudah diberikan pendidikan kesehatan sebesar 23,167. Diketahui pula dari hasil uji T-Dependent nilai p sebesar 0,000, berarti dapat disimpulkan terdapat perbedaan yang bermakna pengetahuan sebelum dan sesudah pendidikan kesehatan melalui media video dan Aplikasi Quizlet.

\section{PEMBAHASAN}

\section{Perbedaan Pengetahuan Sebelum dan Sesudah Pendidikan Kesehatan}

Berdasarkan hasil penelitian pada Tabel 3 , diketahui nilai rata-rata perbedaan antara pengetahuan sebelum (pre-test) dan sesudah (post-test) diberikan pendidikan kesehatan adalah 23,167 dengan standar deviasi sebesar 11,102. Diketahui pula dari hasil uji $T$ Dependent nilai t sebesar 11,43 dengan nilai sebesar p 0,000, berarti dapat disimpulkan terdapat perbedaan yang bermakna pengetahuan sebelum dan sesudah pendidikan kesehatan melalui media video dan Aplikasi Quizlet.

Didukung oleh beberapa penelitian, menurut penelitian Cahyono bahwa adanya 
pengaruh pendidikan gizi terhadap pengetahuan sebelum dan sesudah anemia pada siswi, dengan perbedaan rata-rata sebesar 10,00.(12)

Sejalan dengan penelitian Kusumawati bahwa terdapat perbedaan pengetahuan sebelum pendidikan kesehatan. Pendidikan kesehatan mengenai anemia dan Tablet Tambah Darah (TTD) akan meningkatkan informasi siswi untuk mencegah terjadinya anemia. $^{(14)}$ Tentu dalam memberikan pendidikan kesehatan kepada siswi harus memikirkan media apa yang paling menarik dan membuat informasi yang diberikan akan semakin mudah diserap, karena media merupakan perantara informasi yang ingin disampaikan oleh komunikator.

Seiring dengan kemajuan teknologi, mulai dikembangkan sarana pendidikan kesehatan salah satunya penggunaan video. Kelebihan dari media video yaitu dapat memberikan visualisasi yang baik sehingga memberikan kemudahan dalam proses penyerapan pengetahuan. ${ }^{(10)} \mathrm{Hal}$ ini didukung oleh penelitian yang dilakukan Saban diketahui bahwa pengetahuan tentang anemia meningkat ketika menggunakan media video dibandingkan media leaflet. ${ }^{(11)}$

Seiring dengan kemajuan teknologi, tenaga kesehatan dapat mengembangkan media yang menarik bagi siswi dalam memberikan pendidikan kesehatan. Salah satu media pembelajaran berbasis online yang dapat digunakan yaitu Aplikasi Quizlet.Berdasarkan hasil observasi, saat digunakan Aplikasi Quizlet kemarin sebagai media pembelajaran respon siswi sangat baik. Keunggulan Aplikasi Quizlet dibandingkan aplikasi lain yang sejenis ialah pada Quizlet

Live kita dapat bermain quiz secara berkelompok yang dapat melatih kecepatan dan kerja sama kelompok sehingga siswi lebih paham. Menurut David Mc Clelland, budaya kompetisi pada suatu masyarakat dapat merangsang dan melatih untuk berprestasi dibandingkan jika tidak adanya budaya kompetisi. ${ }^{(15)} \mathrm{Hal}$ ini didukung oleh penelitian Wardana menyatakan bahwa siswa yang menggunakan media pembelajaran dengan Aplikasi Quizlet memiliki respon belajar yang lebih baik dibandingkan menggunakan media konvensional. ${ }^{(13)}$

Tingkat pendidikan seseorang dapat mempengaruhi pengetahuan. Semakin tinggi tingka pendidikan seseorang maka semakin mudah seseorang memperoleh informasi dan hal tersebut akan mempengaruhi pengetahuan seseorang tentang kesehatan. ${ }^{(16)}$ Dapat disimpulkan bahwa media yang digunakan peneliti yaitu video dan Aplikasi Quizlet dalam memberikan pendidikan kesehatan dapat meningkatkan pengetahuan siswi tentang anemia dan Tablet Tambah Darah (TTD).

Dari penelitian di atas dapat disimpulkan adanya pengaruh media yang diberikan yaitu media video dan Aplikasi Quizlet terhadap pengetahuan, hal tersebut dapat diterapkan oleh Puskesmas dalam memberikan pendidikan kesehatan di sekolah. Menurut peneliti, penyebab sampai saat ini puskesmas belum menerapkan penggunaan media video dan Aplikasi Quizlet karena belum adanya Sumber Daya Manusia (SDM) di puskesmas yang mempunyai signifikansi pendidikan IT 
yang memiliki tugas khusus dalam pembuatan video dan aplikasi untuk promosi kesehatan atau pendidikan kesehatan. Hal itu tentu menjadi penghambat puskesmas dalam melakukan pendidikan kesehatan di sekolah melalui media yang sesuai dengan perkembangan zaman.

Dalam hal itu peneliti memberikan saran kepada puskesmas untuk mempekerjakan SDM khusus bersignifikansi pendidikan IT atau bekerja sama dengan pihak ketiga untuk mengembangkan media video dan aplikasi berbasis online agar mempermudah puskesmas dalam melakukan pendidikan kesehatan ke sekolah. Setelah mempunyai media video dan aplikasi berbasis online yang menarik, puskesmas dan Pihak Sekolah dapat bekerja sama dalam memberikan pengetahuan tentang anemia di sekolah dengan mengaktifkan Unit Kesehatan Sekolah (UKS) dalam peranan preventif dan promotif. Dengan mengadakan Program Jum'at Sehat pada hari jumat pada minggu kedua dan keempat setiap bulannya. Dalam program tersebut, puskesmas dan Pihak Sekolah memberikan pengetahuan tentang anemia agar dapat mencegah terjadinya anemia pada siswi dan pengetahuan kesehatan lainnya yang harus diketahui oleh semua siswa/siswi di sekolah, sehingga pengetahuan siswa/siswi tentang kesehatan meningkat.

\section{SIMPULAN DAN SARAN}

Dari penelitian di atas dapat disimpulkan adanya perbedaan yang signifikan antara pengetahuan anemia dan Tablet Tambah Darah (TTD) sebelum dan sesudah pendidikan kesehatan melalui media video dan Aplikasi Quizlet $(p=0,000)$. Diharapkan Puskesmas dan Pihak Sekolah dapat bekerja sama dalam memberikan pengetahuan tentang anemia melalui media video dan Aplikasi Quizlet di sekolah dengan mengaktifkan Unit Kesehatan Sekolah (UKS) dalam peranan preventif dan promotif, sehingga pengetahuan tentang anemia meningkat agar dapat mencegah terjadinya anemia pada siswi. Diharapkan Puskesmas dapat mempekerjakan SDM khusus bersignifikansi pendidikan IT atau bekerja sama dengan pihak ketiga untuk mengembangkan media video dan aplikasi berbasis online agar mempermudah puskesmas dalam melakukan pendidikan kesehatan ke sekolah.

\section{DAFTAR PUSTAKA}

1. Dieny FF. Permasalahan Gizi pada Remaja Putri. Yogjakarta: Graha IImu; 2014.

2. World Health Organization (WHO). The Global Prevalence of Anaemia in 2011. Gevena; 2015.

3. Fikawati D. Gizi Anak dan Remaja. Jakarta: Rajawali Pers; 2017.

4. Kementerian Kesehatan RI. Riset Kesehatan Dasar (Riskesdas) 2013. Jakarta: Kemenkes RI; 2013.

5. SDKI. Survei Demografi dan Kesehatan Indonesia 2012: Kesehatan Reproduksi Remaja. Jakarta: Kemenkes RI; 2012.

6. SDKI. Survei Demografi dan Kesehatan Indonesia 2017: Kesehatan Reproduksi Remaja. Jakarta: Kemenkes RI; 2017. 
7. Notoatmodjo S. Promosi Kesehatan Teori dan Aplikasinya. Jakarta: Rineka Cipta; 2010.

8. Caturiyantiningtiyas T. Hubungan Antara Pengetahuan, Sikap dan Perilaku Dengan Kejadian Anemia Remaja Putri Kelas $X$ dan XI SMA NEGERI 1 Polokarto. J UMS. 2015;111.

9. Kusuma NI. Pengaruh Pendidikan Kesehatan Anemia pada Remaja Putri Terhadap Tingkat Pengetahuan dan Sikap dalam Mencegah Anemia pada Siswi Kelas X SMA Muhammadiyah 5 Yogyakarta. J Stikes Aisyiyah. 2014;

10. Kustandi, C dan Sujipto B. Media Pembelajaran Manual dan Digital. Bogor: Penerbit Ghalia Indonesia; 2011.

11. Saban S. Efektifitas Media Video dan Leaflet Terhadap Pengetahuan Tentang Anemia Siswi SMAN 2 Ngaglik
Media Video dan Aplikasi Quizlet / Devita Sari Sleman. J Aisyiyah. 2017;

12. Cahyono SB. Peningkatan Pengetahuan Siswi Tentang Anemia Setelah Mendapatkan Pendidikan Gizi Dengan Media Video Animasi. J UMS. 2015;2-12.

13. Wardana dan Zakiah. Information Technology-Based Learning (Media Development Applications Quizlet on students in MI DDI Seppange Bone). J Al-Iltizam. 2019; Vol.4 No.1:37-52.

14. Kusumawati dkk. Pendidikan Gizi Peer Educator Dalam Upaya Pencegahan Kejadian Anemia. J Kesmas Indones. 2019;11:36-44.

15. Uno $H$. Teori Motivasi dan Pengukurannya. Jakarta: Bumi Aksara; 2010.

16. Budiman dan Riyanto A. Kapita Selekta Kuesioner: Pengetahuan dan Sikap dalam Penelitian Kesehatan. Jakarta: Salemba Medika; 2014. 